\title{
MASS TRANSFER CORRELATION FOR THE REMOVAL OF COPPER IONS FROM WASTEWATER
}

\author{
N. M. S. Kaminaria, \\ M. J. J. S. Ponte ${ }^{\text {b, }}$ \\ and H. A. Ponte \\ ABSTRACT \\ One of the biggest problems with ore processing in extractive metallurgical \\ industries is the high toxicity of the heavy metals waste content (e.g., \\ copper, lead, nickel and chrome). This work investigates the copper (II) íons \\ removal from aqueous solutions in concentrations up to $1000 \mathrm{ppm}$. \\ Therefore, a fluidized bed electrolytic reactor was used with flow-by \\ configuration considered as a hopeful method due to the large specific \\ surface area and the high mass transfer rate. The performance of the \\ electrochemical reactor was investigated by using different porosities. \\ Dimensionless Sherwood and Reynolds numbers were correlated to \\ characterize the mass transport properties of the reactor, and they were \\ fitted to the equation $\mathrm{Sh}=\mathrm{a} \cdot \mathrm{Re}^{\mathrm{b}} \cdot \mathrm{Sc}^{1 / 3}$. \\ CP. 19011, Curitiba, Paraná, Brasil \\ nice.kaminari@gmail.com \\ ${ }^{\mathrm{b}}$ Universidade Federal do Paraná \\ Departamento de Engenharia Mecânica \\ Keywords: Fluidized bed reactor; Effluent treatments; Copper recovery; \\ Dimensionless correlation \\ mponte@ufpr.br \\ ${ }^{\mathrm{c}}$ Universidade Federal do Paraná \\ Departamento de Engenharia Química \\ hponte@ufpr.br
}

\section{NOMENCLATURE}

\section{A}

electrode surface, $\mathrm{m}^{2}$

constant

constant

concentration, ppm

$\mathrm{C}_{\lim }$ limit concentration, ppm

$\mathrm{C}_{0} \quad$ initial concentration, $\mathrm{ppm}$

D diffusion coefficient, $\mathrm{m}^{2} / \mathrm{s}$

$\mathrm{dh}$ hydraulic diameter, $\mathrm{m}$

$\mathrm{dp}$ particle diameter, $\mathrm{m}$

$\mathrm{I}_{\text {lim }} \quad$ limit current, A

$\mathrm{k}_{\mathrm{m}} \quad$ mass transport coefficient, $\mathrm{m} / \mathrm{s}$

$\mathrm{k}_{1} \quad$ constant $1, \mathrm{~s}^{-1}$

$\mathrm{k}_{2} \quad$ constant $2, \mathrm{~s}^{-1}$

$\mathrm{L}$ characteristic length, $\mathrm{m}$

Re Reynolds number

$\mathrm{Re}_{\mathrm{p}}$ Reynolds number based on particle diameter

Sh Sherwood number

Sc Schmidt number

$\mathrm{t}$ time, $\mathrm{s}$

$\mathrm{t}_{\text {lim }} \quad$ limit time, $\mathrm{s}$

$\mathrm{V}$ velocity of electrolyte, $\mathrm{m} / \mathrm{s}$

$V_{R} \quad$ reactor volume, $\mathrm{m}^{3}$

\section{Greek symbols}

$\mu \quad$ absolute viscosity, $\mathrm{kg} / \mathrm{m} . \mathrm{s}$

$\varepsilon \quad$ porosity

$v$ fluid kinematic viscosity, $\mathrm{m}^{2} / \mathrm{s}$

$\rho \quad$ electrolyte density, $\mathrm{kg} / \mathrm{m}^{3}$

$\delta \quad$ diffusive layer thickness, $\mathrm{m}$

\section{INTRODUCTION}

Copper is a metal of great industrial importance, widely used in electronic industries (Fornari and Abbruzzese, 1999), electroplating and mining. The effluents containing metal ions, even at low concentrations $(0.009 \mathrm{mg} / \mathrm{L}$ for copper, Resolution $357 / 2005$ ), are very toxic effluents. The disposal of untreated effluents can cause various types of pollution such as: extermination of aquatic life and human health related problems.

The most commonly used methods for the removal of metal ions are: precipitation with hydroxides, sulphites or oxalates; chemical or electrochemical ion exchange, reverse osmosis, chemical or physical adsorption, stabilization or solidification, chemical reduction, biochemical remediation and more recently, electrochemical deposition (Rajeshwar and Ibanez, 1997). Precisely effluents with low metal concentrations form toxic effluents. An ideal solution to this problem could be a process to recover and recycle the metal and the water. The classic methods have become unviable due to the large amount of material to be recovered, including the high cost to many companies due the use of chemical reagents and the need to store the large quantities of sludge (environmental liabilities) formed (Bertazzoli et al., 1998).

An alternative potential method is the recovery of metals from dilute solutions using the fluidized bed reactor (Sioda and Piotrowska, 1980; Simonsson, 1984; Langlois and Coeuret, 1989; Widner et al., 
1998; Ruotolo and Gubulin, 2002, Kaminari et al. 2005; Kaminari et al. 2007). The fluidized bed or three-dimensional reactor has been considered promising due to the high specific surface area and high mass transfer coefficients, making the system attractive for various electrochemical processes (Wilkinson, 1971).

However, the electrochemical process has several technological challenges, such as: 1) The decrease of concentrations with time causing low current efficiency, 2) The need for a support electrolyte to be added when the ion concentration is very low 3) interference of the hydrogen evolution and/or oxygen reaction that must be prevented or minimized, 4) The deposition rate and composition of the solution in some cases may promote the production of dendrites or spongy deposits and 5) The need for high flow rates that favor increasing the limit current, and reduce the residence time, providing small removal rates (Rajeshwar and Ibanez, 1997; Ponte, 1998).

The work herein investigates the deposition of copper ion on the particles of particulated reactor, for different porosities $(\varepsilon)$. This parameter is one of the most important of this system, directly related to the charge transfer, and the amount of available charge in the reactor is responsible for the reduction reaction of copper ion. The properties of mass transport from the reactor were characterized by a dimensionless correlation

\section{MATERIALS AND METHODS}

\section{MATERIALS}

The fluidized-bed electrochemical reactor (FBE) was made from acrylic, enabling a better visualization of the process. The rectangular geometry is $180 \mathrm{~mm}$ in length, $370 \mathrm{~mm}$ in height and a thickness of $24 \mathrm{~mm}$. A distributor, consisting of a packed bed of cylindrical polyethylene particles (diameter $=2.5 \mathrm{~mm}$ and height $=1.5 \mathrm{~mm}$ ), was used to distribute the fluid uniformly in the bed. The electrical contact with the fluidized bed consisted of a copper plate (cathode) and the anode was a $\mathrm{Pb} / \mathrm{Sb}$ alloy plate. The reactor consisted of copper particles, $1 \mathrm{~mm}$ in diameter, which served as an electrically conductive bed in direct contact with the plate current feeder (cathode). Is the surface of these particles occurring electrochemical reactions of reduction of copper ion in the solution through the voltage applied to the cell.

An experimental unit was designed to study the recovery of copper ions (Fig. 1).

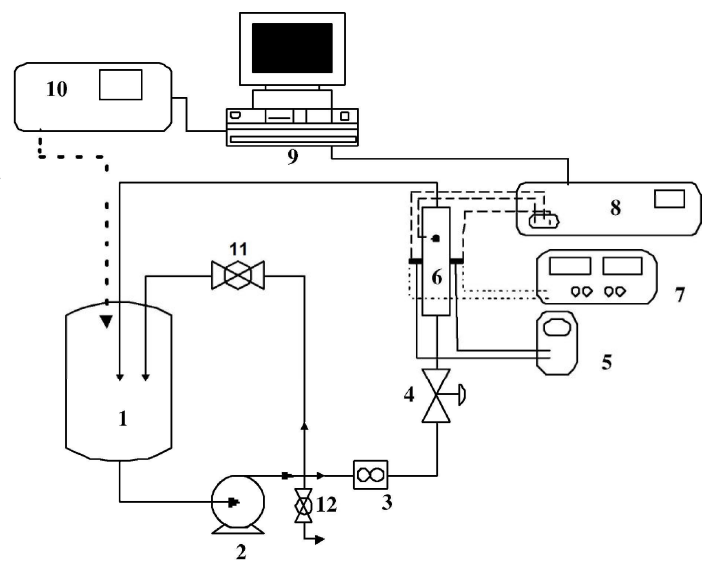

Figure 1. Schematic representation of the experimental units: (1) electrolyte reservoir; (2) centrifugal pump; (3) flow rate digital meter; (4) diaphragm valve; (5) voltmeter; (6) electrochemical reactor; (7) power supply; (8) potentiostat; (9) computer; (10) UV-Vis spectrophotometer; (11) ball valve (by-pass); (12) ball valve (for electrolyte exhaustion).

The fluidized bed electrodes can have two configurations, according to the direction of the current and electrolytic flows, called flow-through and flow-by configuration. In this work it was used the flow-by configuration which the electrolytic flow and the electric current run in perpendicular directions.

All the chemicals used in this study were of analytical grade and deionized water was used to prepare all the $\mathrm{CuSO}_{4}(0.016 \mathrm{~mol} / \mathrm{L}$ approximately $1000 \mathrm{ppm} \mathrm{Cu}$ ions) solution and $\mathrm{H}_{2} \mathrm{SO}_{4}(0.4 \mathrm{~mol} / \mathrm{L})$ as the supporting electrolyte. The electrolyte flow was obtained by means of a centrifugal pump, thus achieving a continuous flow, and the flow control was done through valves. Samples were collected at the beginning and end of each experimental run at predetermined intervals and the concentrations were measured in the spectrophotometer (UV-VIS model FEMTO 600 Plus).

\section{METHODS}

To achieve the objectives of this work the following steps were performed:

a) Experimental Design - to specify the variables to be studied and set the variables values in the experimental runs. The variables used were: porosities $(\varepsilon)(0.40,0.43$ and 0.47$)$ and current (I) $(4.9 \mathrm{~A}, 6.5 \mathrm{~A}$ and $8.0 \mathrm{~A})$. In all experiments the temperature was maintained at around $25^{\circ} \mathrm{C}$.

b) Preparation and execution of experiments - the following steps were used: preparation and storage of electrolyte, filling the bed with the particles to a height of pre-determined bed according to the porosity; adjustment of the current source so that the determined electrical current was known, admission of electrolyte in a 
pre-established flow, setting the electric current source; coupling of the electrical contacts. The experimental runs were designed for the reactor to remain in operation for about 3 hours, during which samples were collected in regular time intervals, in order to monitor the variation of the copper concentration in the electrolyte. At the same time that the samples were withdrawn, the instantaneous potential difference was determined (provided by source).

c) Data treatment - According to Pletcher and Walsh (1990), the system can be modeled satisfactorily as a simple batch reactor. Based on the data of changes in concentrations over time and obtaining the figures of merit, it is possible to determine the conditions for the limit current for each case, and thus develop a correlation between dimensionless groups such as:

$$
\mathrm{Sh}=\mathrm{a} \cdot \operatorname{Re}^{\mathrm{b}} \cdot \mathrm{Sc}^{1 / 3}
$$

where a and b are constant, Sherwood (Sh), Reynolds (Re) and Schmidt (Sc) defined as:

$$
\begin{aligned}
& S h=\frac{k_{m} \cdot L}{D} \\
& \operatorname{Re}=\frac{\rho \cdot v \cdot L}{\mu} \\
& S c=\frac{\mu}{\rho \cdot D}
\end{aligned}
$$

where:

$\mathrm{k}_{\mathrm{m}}=$ mass transport coefficient $\left(\mathrm{m} \cdot \mathrm{s}^{-1}\right.$ )

$\mathrm{L}=$ characteristic length $(\mathrm{m})$ or hydraulic diameter $(\mathrm{dh}) \quad d h=\frac{\varepsilon}{(1-\varepsilon)} \mathrm{dp}$

$\mathrm{dp}=1.10^{-3} \mathrm{~m}=$ particle diameter

$\mathrm{D}=6.10^{-10} \mathrm{~m}^{2} / \mathrm{s}=$ diffusion coefficient

$\rho=1005.6 \mathrm{~kg} / \mathrm{m}^{3}=$ electrolyte density

$\mu=9.29 .10^{-4} \mathrm{~kg} / \mathrm{m} . \mathrm{s}=$ absolute viscosity

$\mathrm{v}=$ velocity of electrolyte $(\mathrm{m} / \mathrm{s})$

\section{RESULTS}

Following the aforementioned experimental procedures, the limit conditions were obtained by analyzing the graphs of concentration versus time. The curve represents a variable-order reaction, i.e., the data fit a particular reaction order at high concentrations and by another order at low concentrations. Based on this study, the limit condition that is the point when the reaction is zero order, the changes for a first-order reaction can be obtained (Figure 2) (Levenspiel, 2000). The zeroorder reaction system is controlled by the current and the first-order reaction system is controlled by mass transport.

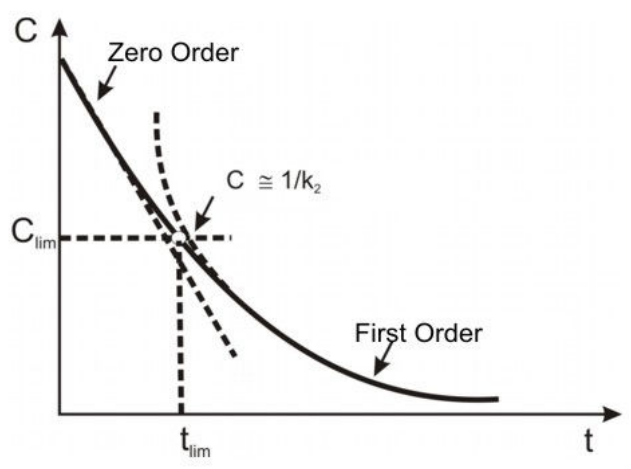

Figure 2. Behavior of a variable-order reaction (Levenspiel, 2000).

In the experiments, the three currents were analyzed (4.9 A, 6.5 A and 8.0 A) for a period of 3 hours. To calculate the $\mathrm{C}_{\mathrm{lim}}$ it was necessary to obtain the value of $\mathrm{k}_{2}$, because $\mathrm{C}_{\mathrm{lim}}=1 / \mathrm{k}_{2}$ via linear regression, thus obtaining the value of $t_{\text {lim }}$. Linear regression was performed according to equation (5).

$$
\frac{C_{0}-C}{\ln \left(C_{0} / C\right)}=\frac{1}{\mathrm{k}_{2}}+\frac{\mathrm{k}_{1}}{k_{2}}\left[\frac{\mathrm{t}}{\ln \left(C_{0} / C\right)}\right]
$$

where:

$\mathrm{C}_{0}=$ initial concentration (ppm)

$\mathrm{C}=$ concentration $(\mathrm{ppm})$

$\mathrm{k}_{1}=$ constant $1\left(\mathrm{~s}^{-1}\right)$

$\mathrm{k}_{2}=$ constant $2\left(\mathrm{~s}^{-1}\right)$

$\mathrm{t}=$ time $(\mathrm{s})$

Figure 3 shows the linear regression curves using equation (5), hence obtaining the results presented in Table 1. The limit condition chosen for this porosity was equal to the current $6.5 \mathrm{~A}$, because for this condition there is a greater predominance of mass transport, the process that starts $1.68 \mathrm{~h}$ after the experiment begins. The same procedures were performed for other porosities, obtaining the results presented in Table 1 and the final limit conditions are in Table 2.

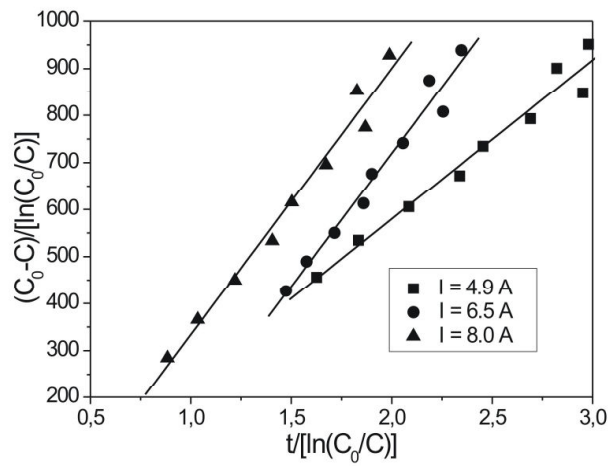

Figure 3. Calculation of $\mathrm{C}_{\lim }$ for $\varepsilon=0.40$ and $\mathrm{I}=$ 4.9 A, 6.5 A and 8.0 A. 
Table 1. Values obtained for the limit condition.

\begin{tabular}{c|c|c|c|c}
\hline Porosity & $\mathrm{I}(\mathrm{A})$ & 4.9 & 6.5 & 8.0 \\
\hline \multirow{4}{*}{0.40} & $\mathrm{k}_{1}\left(\mathrm{~s}^{-1}\right)$ & 3.50 & 1.37 & 2.44 \\
\cline { 2 - 5 } & $\mathrm{k}_{2}\left(\mathrm{~s}^{-1}\right)$ & $10.30 \mathrm{E}-3$ & $2.43 \mathrm{E}-3$ & $4.31 \mathrm{E}-3$ \\
\cline { 2 - 5 } & $\begin{array}{c}\mathrm{C}_{\text {lim }} \\
(\mathrm{ppm})\end{array}$ & 97 & 400 & 232 \\
\cline { 2 - 5 } & $\mathrm{t}_{\text {lim }}(\mathrm{h})$ & 3.33 & 1.68 & 1.95 \\
\hline \multirow{4}{*}{0.43} & $\mathrm{k}_{1}\left(\mathrm{~s}^{-1}\right)$ & 39.18 & 6.85 & 5.24 \\
\cline { 2 - 5 } & $\mathrm{k}_{2}\left(\mathrm{~s}^{-1}\right)$ & $161 \mathrm{E}-3$ & $18.8 \mathrm{E}-3$ & $12.93 \mathrm{E}-3$ \\
\cline { 2 - 5 } & $\begin{array}{c}\mathrm{C}_{\text {lim }} \\
(\mathrm{ppm})\end{array}$ & 6 & 53 & 78 \\
\cline { 2 - 5 } & $\mathrm{t}_{\text {lim }}(\mathrm{h})$ & 4.21 & 3.05 & 2.50 \\
\hline \multirow{4}{*}{0.47} & $\mathrm{k}_{1}(\mathrm{~s}-1)$ & 32.06 & 10.47 & 9.87 \\
\cline { 2 - 5 } & $\mathrm{k}_{2}\left(\mathrm{~s}^{-1}\right)$ & $133 \mathrm{E}-3$ & $29.6 \mathrm{E}-3$ & $22.9 \mathrm{E}-3$ \\
\cline { 2 - 5 } & $\begin{array}{c}\mathrm{C}_{\text {lim }} \\
(\mathrm{ppm})\end{array}$ & 7.5 & 34 & 44 \\
\cline { 2 - 5 } & $\mathrm{t}_{\lim }(\mathrm{h})$ & 4.27 & 3.06 & 2.50 \\
\hline
\end{tabular}

Table 2. Limit condition selected.

\begin{tabular}{c|c|c|c}
\hline $\begin{array}{c}\text { Porosity } \\
(\varepsilon)\end{array}$ & $\mathrm{I}(\mathrm{A})$ & $\mathrm{I}_{\text {lim }}(\mathrm{A})$ & $\mathrm{C}_{\lim }(\mathrm{ppm})$ \\
\hline 0.40 & 6.5 & 6.0 & 400 \\
\hline 0.43 & 8.0 & 4.0 & 78 \\
\hline 0.47 & 8.0 & 5.6 & 44 \\
\hline
\end{tabular}

Table 3. Values of mass transport coefficient $\left(\mathrm{k}_{\mathrm{m}}\right)$.

\begin{tabular}{c|c|c}
\hline Porosity & $\mathrm{I}(\mathrm{A})$ & $\mathrm{k}_{\mathrm{m}}(\mathrm{m} / \mathrm{s})$ \\
\hline \multirow{2}{*}{0.40} & \multirow{2}{*}{6.0} & $1.29 \mathrm{E}-5$ \\
\cline { 3 - 3 } & & $1.26 \mathrm{E}-5$ \\
\hline \multirow{2}{*}{0.43} & \multirow{2}{*}{4.0} & $2.50 \mathrm{E}-5$ \\
\cline { 3 - 3 } & & $2.24 \mathrm{E}-5$ \\
\hline \multirow{2}{*}{0.47} & \multirow{2}{*}{5.6} & $2.82 \mathrm{E}-5$ \\
\cline { 3 - 3 } & & $3.40 \mathrm{E}-5$ \\
\hline
\end{tabular}

Based on the results of Table 2, 3 additional experiments in duplicates were carried out with the new values of $\mathrm{C}_{\lim }$ and $\mathrm{I}_{\mathrm{lim}}$, in order to determine the $\mathrm{k}_{\mathrm{m}}$ in the region where the mass transport phenomenon actually predominates. The $\mathrm{C}_{\lim }$ is now the $\mathrm{C}_{0}$ and the samples were taken at every 15 minutes, which is the minimum for the solution mixture in the reservoir. The $\mathrm{k}_{\mathrm{m}}$ was determined through linear regression in Figure 4, Figure 5 and Figure 6 . Table 3 shows the values of $\mathrm{km}$ calculated using equation (6).

$$
\ln [C(t)]=\ln [C(0)]-\left(\frac{k_{m} \cdot A}{V_{R}} \cdot \mathrm{t}\right)
$$

where:

$\mathrm{C}(\mathrm{t})=$ concentration at time $\mathrm{t}(\mathrm{ppm})$

$\mathrm{C}(0)=$ initial concentration $(\mathrm{ppm})$

$\mathrm{A}=$ electrode surface $\left(\mathrm{m}^{2}\right)$

$\mathrm{V}_{\mathrm{R}}=$ volume of electrolyte $\left(\mathrm{m}^{3}\right)$

The values of $k_{m}$ in Table 3 increase with increasing porosity, this was expected since the increase in porosity causes a decrease in the thickness of the diffusive layer and hence the increase in $\mathrm{k}_{\mathrm{m}}$, because the $\mathrm{k}_{\mathrm{m}}$ values are inversely proportional to the diffusive layer thickness $(\delta)\left(\mathrm{k}_{\mathrm{m}}=\mathrm{D} / \delta\right)$.
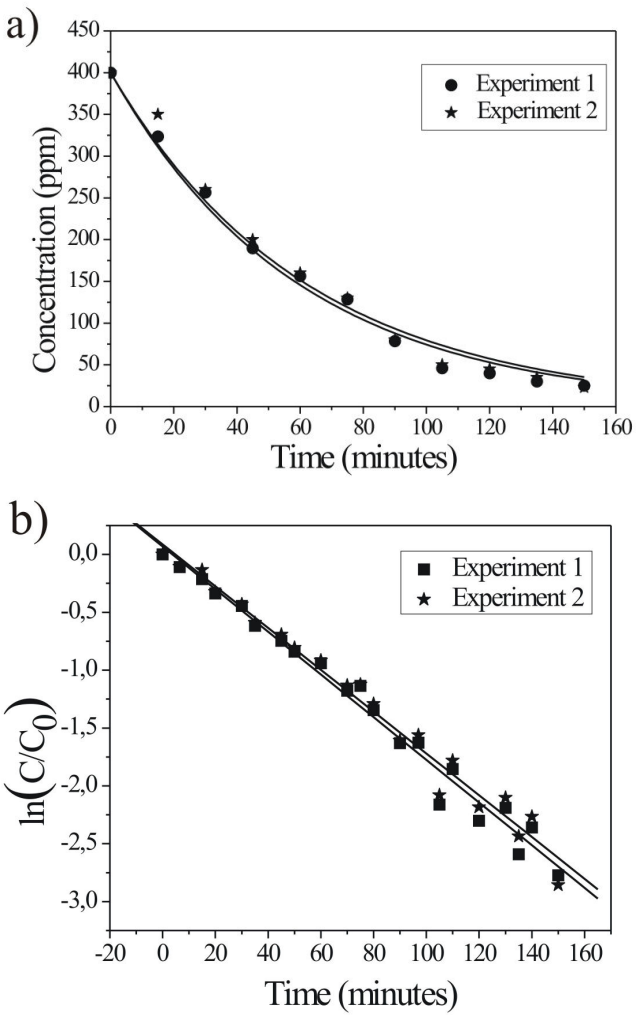

Figure 4. a) Concentration (ppm) versus time (minutes) and $\mathrm{b}) \ln \left(\mathrm{C} / \mathrm{C}_{0}\right)$ versus time (minutes) porosity 0.40 .

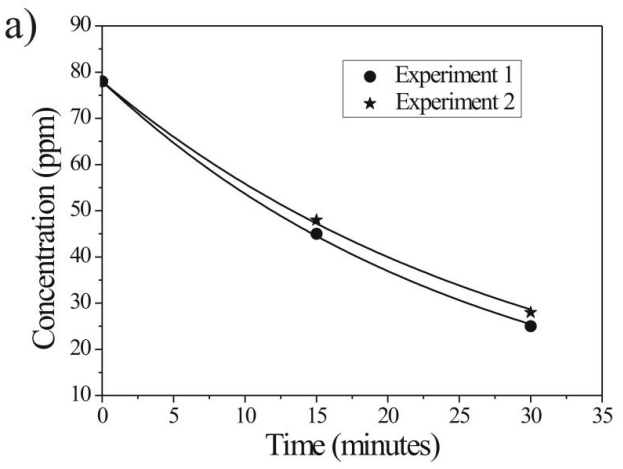


b)

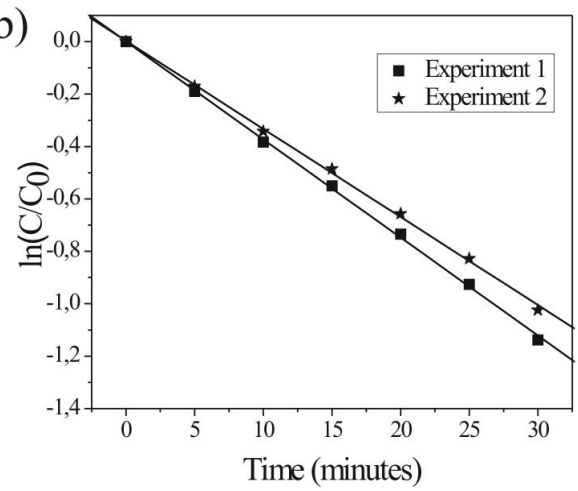

Figure 5. a) Concentration (ppm) versus time (minutes) and b) $\ln \left(\mathrm{C} / \mathrm{C}_{0}\right)$ versus time (minutes) porosity 0.43 .

a)

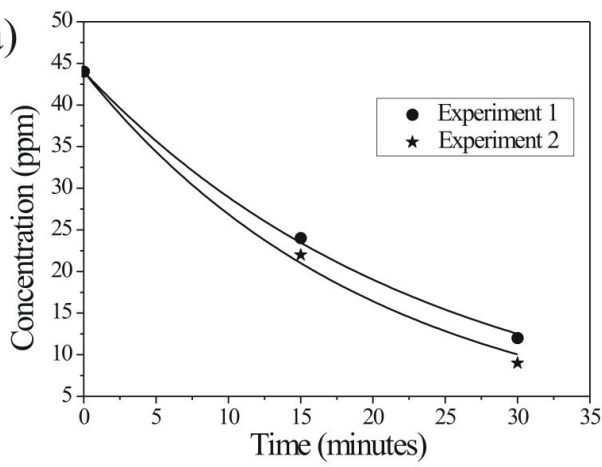

b)

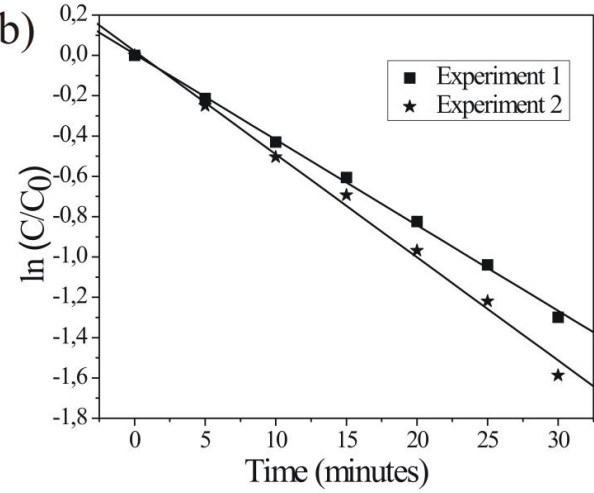

Figure 6. a) Concentration (ppm) versus time (minutes) and $\mathrm{b}) \ln \left(\mathrm{C} / \mathrm{C}_{0}\right)$ versus time (minutes) porosity 0.47 .

The analysis of dimensionless groups is a method to express a correlation when the process of reducing the ion is limited by mass transport in an electrochemical reactor. According to Pletcher and Walsh (1990), the system can be modeled satisfactorily as a simple batch reactor. The correlation was calculated according to equation (1) with the data from Table 4.
Table 4. Parameter values for calculating the correlation.

\begin{tabular}{c|c|c|c|c}
\hline POROSITY & Sh & $\mathrm{Re}_{\mathrm{p}}$ & $\begin{array}{c}\ln \\
\left(\mathrm{Re}_{\mathrm{p}}\right)\end{array}$ & $\ln \left(\mathrm{Sh} / \mathrm{Sc}^{1 / 3}\right)$ \\
\hline \multirow{2}{*}{0.40} & 14.32 & \multirow{2}{*}{66.67} & \multirow{2}{*}{4.20} & $\frac{15.78 \mathrm{E}-2}{$\cline { 5 - 5 }} \\
\cline { 2 - 3 } & 14.02 & & $13.60 \mathrm{E}-2$ \\
\hline \multirow{2}{*}{0.43} & 31.42 & \multirow{2}{*}{110.05} & \multirow{2}{*}{4.70} & $94.28 \mathrm{E}-2$ \\
\cline { 2 - 3 } & 28.21 & & $83.52 \mathrm{E}-2$ \\
\hline \multirow{2}{*}{0.47} & 41.75 & \multirow{2}{*}{145.80} & \multirow{2}{*}{4.98} & 1.23 \\
\cline { 2 - 3 } \cline { 5 - 5 } & 50.31 & & 1.41 \\
\hline
\end{tabular}

The constants $\mathrm{a}$ and $\mathrm{b}$ were obtained from curve $\ln \left(\mathrm{Sh} / \mathrm{Sc}^{1 / 3}\right) \times \ln (\mathrm{Re})$ via linear regression.

With the values obtained above, the correlation can be calculated according to equation (1). The constants $\mathrm{a}$ and $\mathrm{b}$ were obtained from the curve $\ln$ $\left(\mathrm{Sh} / \mathrm{Sc}^{1 / 3}\right)$ vs. $\ln \left(\mathrm{Re}_{\mathrm{p}}\right)$, Figure 7 , via linear regression.

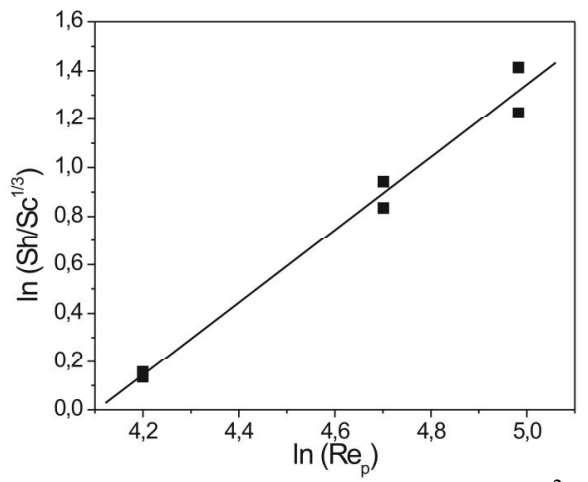

Figure 7. Dimensionless correlation $\left(\mathrm{R}^{2}=\right.$ $98.36 \%)$.

Equation (1) can be written as:

$\mathrm{Sh}=2.14 \mathrm{E}-3 \cdot \mathrm{Re}^{1.5} \cdot \mathrm{Sc}^{1 / 3}$

The result of the adjustment was also evaluated using the parity chart (Figure 8), where the dispersion of residuals is visible.

It can be concluded that the residues are well distributed (Figure 8), which implies that the correlation was able to fit well the experimental data.

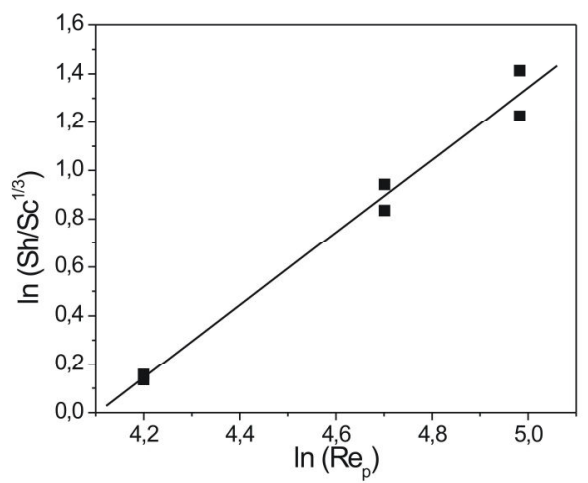

Figure 8. Parity chart. 


\section{CONCLUSION}

In all cases the system was able to reduce the concentration of copper ions to low levels, confirming that the electrochemical reactor bed particles can be used as a single treatment for dilute aqueous solutions of heavy metals. The reduction reaction of copper ions in the electrochemical reactor, unlike what the literature implies, is a controlled process by mixed process, where parallel reactions occur. The correlation was satisfactory, when compared to those obtained in the literature (Simonsson, 1984; Hunsom et al., 2002), thus successful in representing the properties of mass transport.

\section{ACKNOWLEDGEMENT}

The authors would like to acknowledge the financial support received from Coordination for the Improvement of Higher Level Personnel (CAPES) and the Laboratory of Environmental Technology (LTA - UFPR).

\section{REFERENCES}

Bertazzoli, R., Rodrigues, C. A., Dallan, E. J., Fukunaga, M. T., Lanza, M. R. V., Leme, R. R. and Widner, R. C., 1998, Mass transport properties of a flow-through electrolytic reactor using a porous electrode: performance and figures of merit for $\mathrm{Pb}$ (II) removal, Braz. J. Chem. Eng. Vol. 15, pp. 396405.

Fornari, P. and Abbruzzese, C., 1999, Copper and nickel seletive recovery by electrowinning from electronic and galvanic industrial solutions, Hidrometallurgy Vol. 52, pp. 209-222.

Hunsom, M., Vergnes, H., Duverneuil, P., Pruksathorn, K., Damronglerd, S., 2002, Recovering of copper from synthetic solution in 3PE reactor, Science Asia, Vol. 28, pp. 153-159.

Kaminari, N. M. S., Ponte, M. J. J. S., Ponte, H. A. and Neto, A. C., 2005, Study of the parameters involved in designing a particle bed reactor for the removal of lead from industrial wastewater - central composite design methodology. Chem. Eng. J., Vol. 105 pp. 111-115.

Kaminari, N. M. S., Schultz, D. R., Ponte, M. J. J. S., Ponte, H. A., Marino, C. E. B. and Neto, A. C., 2007, Heavy metals recovery from industrial wastewater using Taguchi method Chem. Eng. J., Vol. 126, pp. 139-146.

Langlois, S. and Coeuret, F., 1989, Flowthrough and Flow-by Electrodes of Nickel Foam II. Diffusion convective mass transfer between the electrolyte and the foam, J. Appl. Electrochem. Vol. 19, pp. 51-60.

Levenspiel, O., 2000, Engenharia das reações químicas, Editora Edgard Blucher.
Pletcher, D. and Walsh, F. C., 1990, Industrial Electrochemistry, Second edition, Chapman and Hall, Londres.

Ponte, M. J. J. S., 1998, Estudo da Remoção do íon cobre de solução aquosa diluída em eletrodos de leito particulado. Doctoral Thesis, Instituto de Engenharia Química da Universidade Federal de São Carlos, UFSCar, São carlos, SP. (in Portuguese)

Rajeshwar, K. and Ibanez, J. G., 1997, Environmental Electrochemistry. $1^{\mathrm{a}}$ ed., Academic Press, Londres.

Resolução No 357 - 2005, Conselho Nacional do Meio Ambiente - CONAMA. . (in Portuguese)

Ruotolo, L. A. M. and Gubulin, J. C., 2002, Electrodeposition of copper ions on fixed bed electrodes kinetic and hydrodynamic study, Braz. J. Chem. Eng. Vol. 19, pp. 105-118.

Safarazi, F. and Ghoroghchian, J., 1994, Electrochemical copper removal from dilute solutions by packed bed electrodes, Microchem. J. Vol. 50, pp. 33-43.

Simonsson, D., 1984, A Flow-by Packed-bed Electrode for Removal of Metal Ions from Waste Waters, J. Appl. Electrochem. Vol. 14, pp. 595-604.

Sioda, R. E. and Piotrowska, H., 1980, Flowthrough Electrode for the Retention of Copper, Electrochim. Acta, Vol. 25, pp. 331-334.

Widner, R. C., Sousa M. F. B. and Bertazzoli, R., 1998, Electrolytic Removal of Lead Using a Flow-through Cell with a Reticulated Vitreous Carbon Cathode, J. Appl. Electrochem. Vol. 28, pp. 201-207.

Wilkinson, J. A. E., 1971, Electrolytic recovery of metal values using the fluidized electrodes, Trans. Inst. Mining Metallurgy, Vol. 49, pp.16.

Received: October 30, 2009

Revised: November 30, 2009

Accepted: December 30, 2009 